\title{
Processos de escrita e autoria sobre a ação docente enquanto prática formativa ${ }^{1}$
}

\section{Writing processes and authorship about the teaching practice while formation}

\author{
Marta Nornberg ${ }^{2}$ \\ Gilberto Ferreira da Silva ${ }^{3}$
}

\begin{abstract}
RESUMO
Este artigo apresenta os processos de escrita e autoria enquanto prática formativa. O objetivo é analisar os significados e sentidos atribuídos pelos professores ao trabalho de escrita e autoria sobre sua ação docente. Para isso, analisa a correspondência eletrônica que foi trocada entre professores da Educação Básica e professores-pesquisadores da Universidade envolvidos em um projeto de pesquisa-ação colaborativa. A análise evidencia a escrita como ato solitário e fruto de um trabalho reflexivo caracterizado como árduo, semelhante à gestação e ao trabalho de parto. Embora descrito como penoso, o processo de escrita e autoria sobre a atividade docente é entendido como estratégia eficaz para o processo de formação continuada e como potência para a aprendizagem da docência.
\end{abstract}

Palavras-chave: formação de professores; pesquisa-ação colaborativa; escrita e autoria docente.

\begin{abstract}
This article presents the writing process and authorship while formation. The aim is to analyze the meanings and significance attributed by teachers to the work of writing and authorship about their teaching action. For this purpose,
\end{abstract}

DOI: $10.1590 / 0104-4060.31359$

1 Agradecemos ao Conselho Nacional de Desenvolvimento Científico e Tecnológico $(\mathrm{CNPq})$ pelo apoio financeiro para a realização desta pesquisa. Uma versão preliminar deste texto foi apresentada na 34 ${ }^{\mathrm{a}}$ Reunião Anual da Anped, em 2011.

2 Universidade Federal de Pelotas. Faculdade de Educação. Pelotas, Rio Grande do Sul, Brasil. R. Alberto Rosa, nº 154. Porto do Várzea. CEP: 96101-770.

3 Centro Universitário La Salle. Programa de Pós-graduação em Educação. Canoas, Rio Grande do Sul. R. Victor Barreto, nº 2288. Centro. CEP: 92010-000. 
the electronic mails held between teachers of Basic Education and research professors at the University involved in a project of collaborative action research were analyzed. The analysis highlights writing as a solitary act and a result of hard work characterized as reflective, similar to pregnancy and labor. Although described as painful, the process of writing and authorship about the teaching activity is understood as an effective strategy for the process of continuing education and as a powerful element for teaching learning.

Keywords: teacher education; collaborative action research; writing and teaching authorship.

\section{Introdução}

"De tudo quanto se escreve, agrada-me apenas o que alguém escreve com o próprio sangue. Escreve com sangue e aprenderás que sangue é espírito" (NIETZSCHE, 2006, p. 45). Na escola, e sobre o que nela se faz, tudo parece ser algo decorrente de um processo que brota entre dores e lágrimas, alegrias e risos. Escrever ainda é, algumas vezes, a tecnologia que fragiliza nossa forma de estar professor e, talvez, por isso, seja comumente dito que ler ainda é mais fácil do que escrever!

Este artigo, embasado nos pressupostos metodológicos da pesquisa-ação colaborativa, apresenta e analisa os significados e sentidos atribuídos pelos professores ao processo de escrita e autoria sobre sua ação docente, articulando-os ao campo de estudos da formação de professores, especialmente os que contemplam a narrativa do professor como elemento autoformativo (WARSCHAUER, 2001, CUNHA, 1997). Tal aposta deve-se ao fato de que compreendemos os registros escritos dos professores sobre a sua prática pedagógica como forma de desenvolvimento pessoal e profissional e dispositivo capaz de auxiliar os professores e o coletivo da instituição a conhecer e repensar suas práticas pedagógicas. A reflexão aqui desenvolvida sustenta a hipótese de que o processo de escrita e autoria realizado pelo professor e pela professora sobre sua atividade docente constitui-se em estratégia eficaz de formação continuada e como potência formativa.

Os professores e as professoras, sujeitos da pesquisa, fazem parte da equipe de trabalho de um centro de capacitação em educação inclusiva e acessibilidade, situado no município de Canoas/RS. Desde 2007, esses profissionais apoiam as escolas municipais, auxiliando no processo de capacitação dos professores e realizando o atendimento especializado às crianças e jovens com necessidades 
educativas especiais. São profissionais com formação em diferentes áreas do conhecimento, como Psicopedagogia, Pedagogia, Psicomotricidade, Fonoaudiologia, Artes, Educação Física e Psicologia. Com a ampliação do serviço e da política de inclusão no município de Canoas, o desafio da equipe de profissionais desse centro tem sido o de reconstruir a proposta pedagógica que sustenta os serviços educativos oferecidos e definir funções específicas mediante a construção de seu plano de ação, especialmente aquelas que são realizadas no âmbito da formação continuada dos professores das escolas da rede municipal. Portanto, duplamente, o desafio do centro é o de atender crianças e jovens com necessidades educativas especiais e, também, realizar atividades de formação dos professores que atuam nas escolas em que estudam as crianças e jovens em situação de inclusão.

Por isso, pensar sobre o seu processo autoformativo e experimentar estratégias formativas têm se constituído tarefa contínua, o que tem demandado aos profissionais do centro repensar também o seu espaço de formação continuada e as atividades que constituem o programa de formação de professores, especialmente em relação às políticas de inclusão e à construção de práticas pedagógicas inclusivistas.

O desafio de pensar estratégias de formação para os professores da rede tem instigado os profissionais do centro a repensar sua prática pedagógica e a sistematizar os saberes da prática de atendimento especializado que cada um deles tem constituído ao longo do exercício docente. Nesse contexto, os profissionais do centro, durante as etapas iniciais da pesquisa-ação em desenvolvimento, indicaram a necessidade de sistematizarem a sua prática mediante o exercício da escrita.

\section{Aspectos teórico-metodológicos da pesquisa}

Embora não seja unânime, é inegável o valor da obra de Kurt Lewin (1890-1947) como referência básica para a discussão sobre os usos da metodologia da pesquisa-ação participante. Lewin (2006) enfatiza a possibilidade de se ultrapassar o sentido de fazer pesquisa social experimental para um novo modelo em que se agregam o compromisso político dos envolvidos na pesquisa (pesquisadores e pesquisados) e a transformação da realidade em que se inserem, promovendo mudanças nos comportamentos sociais do grupo.

No processo de desenvolvimento do trabalho de pesquisa, os princípios da pesquisa-ação que orientaram sua execução metodológica seguiram algumas 
proposições: ação conjunta entre pesquisador-pesquisados; realização da pesquisa em ambientes onde acontecem as próprias práticas; organização de condições de autoformação e emancipação dos sujeitos da ação; ressignificações coletivas das compreensões do grupo, articuladas com as condições sócio-históricas. (FRANCO, 2005).

A primeira fase da pesquisa compreendeu etapas relativas à construção do diagnóstico, definindo as prioridades de ação, seguidas do processo de planejamento. A segunda fase da pesquisa dedicou-se à análise, interpretação e elaboração de conclusões a partir dos registros, documentos, arquivos com amostras de trabalhos, etc., produzidos durante a primeira fase. Desse processo, duas ações foram propostas: a primeira se referia ao processo de re-elaboração das estratégias de ação, garantindo o movimento espiralado, próprio da metodologia da pesquisa-ação; a segunda ação previa e organizava, de forma mais intensa e sistemática, a produção textual reflexiva, momento em que se confrontava a experiência feita com outras experiências para além do seu contexto de origem, no sentido de ampliar a capacidade de refletir sobre o que se faz na própria ação, investindo em seu processo de formação, mediante a reflexão sobre a ação, e autoria docente, mediante a produção de textos.

Cabe informar que a organização e a publicação de um livro sobre as atividades do centro foi uma das prioridades indicadas na primeira fase da pesquisa. O grupo de profissionais entendia que a escrita de textos - publicados em formato de livro - se tornaria um meio produtivo para refletir sobre os pressupostos teóricos e metodológicos que sustentam a proposta e a prática pedagógica do centro de atendimento. Apostavam que o material poderia servir como apoio em processos formativos dos professores da rede municipal e como alternativa eficaz para informar e divulgar aspectos que constituem o processo de atendimento às crianças e jovens com necessidades educativas especiais ao público em geral.

Duas dimensões compuseram o trabalho de mobilização para a reflexão e sistematização da prática pedagógica e a consequente atividade de escrita dos artigos. A primeira dimensão referiu-se aos espaços coletivos de encontros presenciais do grupo de profissionais. Esses momentos tinham por objetivo refletir sobre as necessidades emergentes do trabalho do grupo e a criação de estratégias de ação através do planejamento coletivo. Dessa primeira dimensão, emergiu a meta de transformar em texto as reflexões e práticas desencadeadas pelos profissionais a partir de suas ações cotidianas. A segunda dimensão dizia respeito ao processo de acompanhamento da escrita, feita de forma virtual, recorrendo ao uso da correspondência eletrônica como estratégia de intercâmbio, acompanhamento e orientação da escrita, a ser realizada entre pesquisadores da Universidade e profissionais do centro. Em alguns casos, o recurso da cor- 
respondência eletrônica também foi utilizado entre os próprios profissionais do centro como forma de escrita coletiva e apoio mútuo entre colegas, especialmente naqueles momentos em que o pânico da tela vazia se instalava.

Reali, Tancredi e Mizukami (2010), em pesquisa que se ocupou de criar um programa de mentoria online para professores iniciantes, indicam que a pesquisa e o uso da correspondência eletrônica como estratégia formativa têm se constituído uma ferramenta relevante. Explicam que, devido aos tempos e espaços - muitas vezes encurtados pela sobrecarga de trabalho, pelas distâncias entre os lugares de trabalho e destes em relação à Universidade -, os recursos de comunicação via online têm permitido que se mantenham em contato professores experientes, professores iniciantes e professores universitários.

Enquanto pesquisadores e formadores de professores nas instituições em que atuamos, o movimento que propusemos ao grupo de professores foi sustentado pela aposta de que os recursos disponibilizados pela educação a distância permitem ampliar as formas de interlocução, favorecendo, dessa forma, que o desenvolvimento profissional aconteça em outros espaços e tempos, para além dos momentos em que professores se encontram, fisicamente, na instituição de trabalho. Cada vez mais pessoas possuem acesso à internet, o que inclusive tem facilitado, especialmente entre os professores, as trocas e as possibilidades de discussão sobre o trabalho pedagógico realizado. Considerando essa realidade, propomos o acompanhamento ao processo de escrita feito pelos profissionais mediante o intercâmbio e a discussão de seus textos por meio da correspondência eletrônica.

O processo de construção da escrita deu-se entre dezembro de 2010 e julho de 2011, com a finalização dos textos para publicação em formato de coletânea. Ao longo desse período, várias correspondências eletrônicas foram trocadas, momentos em que a escrita era revisada pelos pesquisadores no sentido de indicar possibilidades de análise, referências de apoio teórico, críticas ao texto, estímulos à continuidade do registro. Também correspondências com um conteúdo mais motivador foram enviadas aos professores e às professoras do centro pelos professores-pesquisadores a fim de garantir o envolvimento e a participação efetiva no processo de escrita.

Para melhor localizar o universo sobre o qual estamos nos referindo, descrevemos quantos foram os professores e textos produzidos. Dez textos foram escritos e desses um foi produzido por um grupo de quatro pessoas, dois em duplas e oito de forma individual, envolvendo 15 dos 20 profissionais que atuam no centro. Um professor não participou do processo de escrita textual. Dois professores não conseguiram finalizar o trabalho. Outros dois iniciaram suas atividades quando o processo de escrita já havia sido finalizado e o material produzido se encontrava em fase de revisão e editoração. 
É possível sustentar que as práticas colaborativas de formação docente aliam a busca pelo aperfeiçoamento do profissional da educação à análise crítica do seu fazer pedagógico. Tal tendência toma como uma de suas referências o exercício da capacidade reflexiva do educador sobre seu próprio fazer educativo e propõe que o aperfeiçoamento do profissional da educação seja concebido como um ato permanente. Entendemos ser preciso olhar para o que o professor faz no cotidiano escolar a partir do conhecimento que é por ele produzido, tomando como base suas crenças e valores, certezas e incertezas, conflitos e possibilidades de ação.

Nesse sentido, é preciso considerar como conteúdo para o processo formativo as questões e situações indicadas pelo professor a partir do seu contexto de docência. Do ponto de vista metodológico, pesquisadoras brasileiras têm lançado mão da narrativa como alternativa tanto na pesquisa como no ensino (CUNHA, 1997), entendendo a narrativa ou o registro escrito, em formato de texto, de tipo diário ou outro suporte, como elemento autoformativo (WARSCHAUER, 2001). Cunha (1997) apresenta a narrativa como instrumental educativo, como recurso de grande valor tanto na pesquisa como no ensino e, no contexto em que desenvolvemos esta pesquisa, também a reconhecemos como recurso indispensável à atividade formativa. A pesquisadora explica que o professor constrói sua performance e vai constituindo-se como docente a partir de inúmeras referências que têm inscrição em sua história familiar, escolar, acadêmica, em seu ambiente de trabalho e inserção cultural.

Para Warschauer (2001, p. 185), “a escrita da própria experiência é oportunidade com grande potencial formativo, seja nos moldes de diários, seja em textos narrativos das experiências, sobretudo quando se trata de estratégia coletiva de análise de práticas". Em seu estudo, a autora ainda faz referência ao fato de que escrever significa imprimir o próprio pensamento, o que, ao contrário da prática de copiar e ou reproduzir a ideia ou palavra alheia, geralmente dominante na escola, permite a criação de um processo em que, além de se reconstruir sua relação com a escrita, também se dá ao professor condições para oferecer aos seus alunos outro tipo de experiência e relação com a escrita.

Carlos e Pereira (2011) organizam em seu texto registros de duas experiências de pesquisa e formação em que a escrita foi assumida como dispositivo de formação em educação. As autoras relatam que a escrita permite ao profissional, durante o processo de escrita das ações realizadas, experimentar processos complexos que o auxiliam a organizar o pensamento sobre a ação. Dessa forma, ao escrever, criam-se condições para clarificar as teorias que orientam a ação.

Marcolino e Mizukami (2008) apresentam contribuições para a formação quando analisam narrativas e reflexões produzidas pelo profissional, durante suas atividades, evidenciando elementos formativos que decorrem do processo de 
reflexão-sobre-a-ação. Afirmam que "o processo de narrar a própria experiência possibilita ao sujeito reconstruir sua trajetória e lhe oferece novos sentidos, estabelecendo uma relação dialética entre experiência e narrativa, mediada pelos processos reflexivos" (p. 542).

Tais experiências formativas nos serviram de inspiração e apoio teórico na medida em que mostram a potência da escrita e da autoria para o desenvolvimento profissional. Ao mesmo tempo, percebe-se que os professores também se tornam mais engajados com seus alunos em seu processo de aprendizagem. Ao analisarmos os significados e sentidos atribuídos à experiência de escrita e autoria, registrados na correspondência eletrônica que foi trocada entre os professores e destes com os pesquisadores, foi possível perceber que, mesmo que em pequena medida, os professores e as professoras do centro constituíram redes de apoio e estímulo à escrita durante o processo de elaboração dos textos.

\section{Análise do conteúdo das correspondências eletrônicas}

Para atender à intenção de analisar os sentidos atribuídos pelos professores e professoras ao seu processo de escrita e autoria sobre sua ação docente, tomamos como compreensão de sentido tudo aquilo que organiza de modo ontológico e teleológico o modo-de-ser docente. Do ponto de vista teórico-metodológico, nos apoiamos na reflexão de Gaston Pineau (2000, p. 31-56) sobre o que denominou de três sentidos do sentido. O primeiro consiste na busca da significação da significação, ou seja, aquela atividade que coloca "as sensações e as preocupações sobre a orientação da ação entre parênteses para chegar à reflexão pura" (PINEAU, 2000, p. 44), constituindo uma mobilização reflexiva contínua do e sobre o logos. O segundo é o da sensação, aquele que permite a conexão vital imediata com as origens do seu meio ambiente vital, conexão com características inconscientes, pois mediante a sensação ainda experimentamos, temporariamente, condutas próprias do mundo animal e do mundo vegetal. É por meio da sensação que produzimos e experimentamos o conhecimento intuitivo. O terceiro sentido é o da direção dos movimentos, menos utilizado durante o transcurso da história porque "é uma porta de entrada de política e de estratégia de ação [...] polêmica, prática, pragmática, que impõe colocar a mão na massa, implicar-se, engajar-se, decidir" (PINEAU, 2000, p. 51). O sentido da direção dos movimentos é aquele que nos remete aos aspectos éticos que sustentam a reflexão e a ação docente. 
Ao fazermos o levantamento e organização das conversas realizadas durante as várias trocas de correspondência eletrônica, localizamos dois sentidos que sintetizam, em um primeiro momento, a ênfase que recaiu sobre o conteúdo dos e-mails.

O primeiro sentido evidencia uma relação do trabalho de escrita com as experiências pessoais dos profissionais, principalmente vivências que se referem ao universo feminino.

O segundo sentido mostra as dificuldades vividas durante o processo de escrita, o exercício de se colocar no texto, especialmente de fazer o registro reflexivo, como autor de uma prática pedagógica ou, ainda, de transformar em texto aquilo que é vivido na ação educativa.

Nos dois sentidos, tais aspectos foram marcados pela escrita solitária, que raramente foi rompida por ações de parceria e solidariedade no processo de reflexão teórica, algo que poderia ter sido realizado com outros colegas, com os pesquisadores ou pelo próprio exercício de aprofundamento conceitual. O apoio e o estímulo à escrita aconteciam pela "pressão" de que era preciso escrever algo para alcançar a meta posta em relação à produção de artigos para publicação do livro.

A seguir apresentamos uma análise dos registros encontrados nas correspondências escritas pelas professoras e pelos professores do centro aos professores-pesquisadores.

\section{a) O recurso da experiência feminina como sentido atribuído ao processo de escrita}

Dentre os sentidos que emergem do campo empírico evidencia-se a dificuldade que é pensar sobre o que se faz e, consequentemente, organizar, em texto escrito, aquilo que se pensa sobre o que se faz. O registro de uma das participantes da pesquisa reitera essa percepção, na medida em que mostra que o processo de reflexão e escrita é comparado com vivências pessoais e próprias do universo feminino, que é o da gestação. As vivências do período de gestação servem como imagens descritivas sobre a experiência de refletir sobre sua prática pedagógica e, principalmente, sobre o próprio exercício de fazer a produção escrita:

Demorou, mas nasceu! Melhor dizendo, está nascendo... Estou enviando meu artigo... Melhor, parte dele ... [...] Vou explicar: Como a minha escrita foi uma gestação muito difícil, na verdade, eu quase nem fiquei grávida, pois não estava conseguindo conceber, estou te mandando o que fiz até agora, um artigo semi-pronto, inacabado, com ideias "jogadas" para a cada 
momento serem mais elaboradas. Como o prazo está quase esgotando e eu não havia me manifestado... Dá uma lida e uma opinião... MAS QUE FIQUE CLARO: “ESTÁ INACABADO!” O que está em amarelo é para ser terminado... (Professora M., 13/04/2011).

Outros dois registros deixam evidente a relação umbilical com o resultado da reflexão - o texto escrito - e o reconhecimento de que foi um trabalho árduo, chegando a ser comparado ao trabalho de parto.

Após um longo trabalho de parto, nasceu o filho da Z. Por gentileza, trate-o com muito carinho e dê seus cuidados para que o desenvolvimento seja normal (apesar de gostarmos de inclusão). Deu muito trabalho este parto, quase que o bebê não nasce. Abraços e aguardamos o retorno. Z. e L. (mãe e madrinha-parteira). (Professora L., 01/04/2011).

Este foi mais um parto difícil, mas que resultou numa bela criança. Olhe com carinho para o artigo da N. (Professora D., 16/04/2011).

Nota-se que a caracterização como "trabalho de parto" é feita pelas colegas que, em ambas as situações, se incumbiram da tarefa de enviar o texto aos professores-pesquisadores. A alusão à "gravidez", ao "trabalho de parto" e ao "nascimento" talvez possa sintetizar nessa primeira direção o processo de construção da escrita, elemento importante na formação de professores reflexivos. Como bem lembra Alarcão, "a reflexão na ação acompanha a ação em curso e pressupõe uma conversa com ela. Refletimos no decurso da própria ação, sem a interrompermos, embora com breves instantes de distanciamento e reformulamos o que estamos a fazer enquanto estamos a realizá-lo" (2010, p. 54).

Da gestação ao trabalho de parto e nascimento à entrega do "filho parido" (o artigo) a quem fica incumbido de vê-lo e cuidá-lo (os professores-pesquisadores), um dos aspectos que se observa nesse processo é a dificuldade em deixar que o texto encontre interlocutor, neste caso, os professores-pesquisadores da Universidade que se dispõem, pela interação e conversação, a contribuir para que o texto possa deslocar-se da experiência feita, marcada por uma escrita geralmente apenas descritiva, para um momento em que o texto seja problematizado mediante a interface e o confronto com outros estudos. Os textos que chegavam, "nascidos como filhos paridos de forma árdua", somente eram enviados aos pesquisadores porque já tinham sido, de alguma forma, considerados como "maduros para nascer" por suas "mães", as professoras-autoras. 
Esse movimento de troca, via correspondência eletrônica, privilegiado e assumido pelos pesquisadores da Universidade como um dos objetivos do trabalho de leitura e orientação, pautava-se na compreensão de que o estímulo à escrita sobre a experiência de docência se constitui como formador e estimulante da reflexão crítica sobre a prática. Consequentemente, entendíamos que a troca poderia ser tomada, também, como elemento formativo à medida que, além do registro, poder-se-ia, no momento da discussão sobre a escrita, estabelecer leituras e interlocuções com autores que poderiam referenciar, auxiliar ou ampliar o que cada professora-autora pensava sobre o que realizava em sua prática pedagógica.

Embora constatando que a escrita tornava-se, muitas vezes, para muitas professoras, uma tarefa difícil, enquanto pesquisadores da Universidade, buscávamos por meio do estímulo garantir o movimento de escrita, explicitando, mediante a orientação virtual, quais eram as leis de funcionamento, os valores e as ações que organizavam e sustentavam os processos de autoria e produção científica.

Não é difícil, considerando as alusões à gestação e ao trabalho de parto, compreender a dificuldade em liberar o texto. A grande maioria dos professores envolvidos no trabalho apresentou essa característica. Alguns, inclusive, recorreram primeiro a um colega, para, só então, disponibilizar o texto escrito para os professores da Universidade. Tal aspecto invoca o lugar histórico que a Universidade tem ocupado na relação com a Educação Básica, e o lugar que tem delegado aos educadores, um lugar muitas vezes caracterizado pelo de atuar como meros informantes para as investigações levadas a cabo no ambiente universitário.

Desencadear um processo em que se resgata o lugar dos profissionais da educação como protagonistas é, em um primeiro momento, atrativo e convincente. Entretanto, torna-se, num segundo momento, penoso, na medida em que se dá seguimento à proposta de trabalho que, no nosso caso, mesmo amparados pela metodologia da pesquisa-ação, perseguindo a dinâmica espiralada, mostra os impactos e reservas que professores e professoras possuem para, primeiro, escreverem sobre sua prática docente e, segundo, socializar seu texto, que carrega sua reflexão teórica sobre a prática pedagógica desenvolvida.

Um estudo realizado por Lüdke (2009), em que relatos de pesquisa feitos por professores da Educação Básica são avaliados por professores-pesquisadores da Universidade, constata que o envolvimento de professores em processos de pesquisa-ação tem contribuído para o seu desenvolvimento profissional. Zeichner (1992) também constatou em seus estudos sobre a formação de professores que a pesquisa-ação tem se constituído como possibilidade de produção de conheci- 
mento pelo professor, auxiliando em sua preparação como profissional reflexivo e qualificando sua forma de analisar a própria atividade docente empreendida.

Nesse contexto, cabe discutir os critérios que se têm utilizado para validar a pesquisa do professor da Educação Básica. Sabe-se que, com base em um determinado conjunto de preceitos academicistas, muitas vezes se diferencia e se caracteriza o que o professor da Educação Básica escreve como descrição ou relato de experiência. Mesmo quando o exercício de reflexão sobre a ação pauta-se pela indicação dos elementos teóricos e dos processos metodológicos empreendidos, procurando indicar de forma rigorosa os procedimentos de pesquisa adotados, ainda impera, sobre o texto do professor, um olhar que não o reconhece, de todo, como um relato de pesquisa da prática pedagógica. A pesquisa empreendida por Lüdke evidencia esse processo. Com base no estudo realizado, é possível constatar que, embora se reconheça a necessidade de que todo professor se constitua como pesquisador de sua prática, ainda não se consegue avaliar sua produção numa dimensão que vá além dos aspectos científicos tradicionais.

As referências ao universo feminino, considerando os aspectos acima descritos, podem ser aqui entendidas como uma forma de manifestar a insegurança que se vive em relação ao tipo de apreciação que poderá ser feita sobre o texto que se escreveu. De algum modo, dizer que foi um "trabalho de parto árduo" coloca o professor-pesquisador no lugar de quem, no mínimo, se sentirá fragilizado e se sentirá convocado a "cuidar" do "filho parido" de outra forma, respeitando a própria condição da mãe, que sofreu as dores do parto, que é, nesse caso, a experiência de fazer acontecer o processo e o movimento da escrita e da autoria reflexiva sobre a prática pedagógica.

Entretanto, em processos em que se aposta na escrita como dispositivo de formação, para que o professor possa constituir-se como pesquisador de sua prática, é preciso que haja, segundo Maldaner (1999), no processo formativo e avaliativo, o deslocamento de uma racionalidade técnica para uma racionalidade da prática, o que exige que as situações da prática sejam abordadas em sua complexidade, para que a partir dela se produza conhecimento, através da pesquisa.

A resistência para compartilhar e deixar circular o texto escrito parece expressar a dificuldade que ainda é, para o professor da Educação Básica, constituir e construir conhecimento sobre a ação pedagógica que realiza, especialmente porque isso requer espaço-tempo para a reflexão e apropriação de dimensões teóricas. Tal tarefa exige contemplar e articular, ao mesmo tempo, rigorosidade e crítica teórica com a intensidade descritiva do cotidiano da experiência didático-pedagógica realizada. 


\section{b) Solidão e solidariedade no processo da escrita}

Nos registros das mensagens eletrônicas analisados, percebe-se que o foco ora se centrava no processo, ora na finalização do produto, qual seja: o texto pronto. Sabemos que a escrita é marcada pelo momento de solidão e resulta de um trabalho que muitas vezes é mais solitário do que coletivo. Exige o exercício de autorreflexão e a construção de estratégias que permitam a autoria. Fazendo alusão às reflexões de Bianchetti (2008) sobre o processo de autoria na pós-graduação, é possível afirmar que o ato de escrever extrapola o âmbito profissional porque, muitas vezes, evidencia sentimentos de insegurança, de medo da exposição, de desconforto e de vulnerabilidade. Afinal, se está na condição de professor que ousa escrever sobre sua própria prática, intencionando a produção de conhecimento pedagógico. No próximo depoimento percebem-se tentativas de construção de estratégias distintas para vencer o medo de expressar suas ideias através da escrita:

Desculpa. Sei que não mantive contato. Tenho tido dificuldade de me colocar por escrito. Mas sempre tinha a esperança de ainda conseguir escrever e vencer o medo. Cheguei a pensar em ouvir o que o colega $\mathrm{C}$. me sugeriu: te mandar um artigo que eu fiz há um ano atrás. Mas achava que não combinava com esta publicação por ser ela específica do CEIA. Enfim, acabei não fazendo nem uma coisa nem a outra. É difícil pra mim encarar esta sensação de frustração, que alias, não foi a única nos últimos tempos. Estou te pedindo que, se ainda for possível me permita estar presente neste trabalho de alguma forma. Se não for possível, paciência. Assumo meu entrave. To te mandando em anexo o artigo do qual comentei, mas, independente de qualquer coisa vou escrever algo hoje e te mandar. Se não puder entrar no livro, pelo menos eu tentei (Professora S., 11/04/2011).

A indicação desses sentidos atribuídos pelos professores e pelas professoras ao processo de reflexão e escrita sobre sua ação docente mostra que há, em gestação - seguindo a imagem explicitada -, um fazer autoral. Observa-se também a complexidade com que se move o profissional da educação em seu cotidiano: a falta do exercício da escrita, do registro do que se faz na Educação Básica; os medos que o acompanham, desde a formação inicial, e que insistem em permanecer, constituindo uma relação de temeridade e impotência com o ato de escrever; o conflito permanente entre o desejo da participação e da inovação, por meio da escrita; as limitações dos tempos formativos durante a ação educativa. 
A Z. está enlouquecida com o artigo. Não conseguiu te enviar. Fiz o socorro. Dá uma olhada e me avisa qualquer necessidade de ajuste, que tentarei ajudá-la. (Professora H., 27/04/2011).

Não sei se posso me candidatar para que o artigo saia no livro, mas enfrentei um duro processo de negação e ainda não estou satisfeita com o texto, mas não consigo mais trabalhar. (Professora G., 02/05/2011).

Nossa aposta como professores-pesquisadores centra-se na construção de estratégias que permitam romper com estes atravessamentos e sentimentos que limitam e impedem a reflexão, especialmente a que se pode fazer mediante a produção escrita. Apostamos que, exercitando a escrita reflexiva, o professor passa a realizar com maior autonomia a análise de seu contexto, o registro e a articulação teórico-reflexiva, o que lhe permite avaliar, revisar, ampliar o que faz enquanto docente. Entendemos que a ampliação de estratégias de trabalho colaborativo entre o pesquisador da universidade e o professor da rede produzirá experiências dialógicas e a construção conjunta de conhecimentos, desde que estejam pautados em uma dinâmica reflexiva e investigativa da prática. Dessa forma também será possível contribuir para o desenvolvimento de capacidades reflexivas em ambiente de diálogo e para a autonomia profissional compartilhada, trazendo elementos para a construção coletiva e processual de estratégias formativas de intervenção (COMPIANI, 2006).

Retornando ao intercâmbio dos textos via correspondência eletrônica, observamos que nas interações daqueles profissionais que venceram a resistência ao processo de escrever, após o envio das primeiras escritas, as interações seguintes se davam em um movimento mais solto, mais flexível, menos truncado e com características que se aproximavam à ideia de parceria e colaboração. Nessa direção, um registro: "Vamos aos 'finalmente' do artigo! Escrevi a introdução, refiz as tuas considerações. Deixei as observações e fiz outras na cor vermelha para a tua análise. Estou a disposição para modificar o que precisa ser modificado para que o artigo fique 1000!!!!!" (Professora T., 07/04/2011).

Em outro momento de interlocução, a mesma educadora assim escreve em seu e-mail enviado aos professores-pesquisadores da Universidade:

Eu custo a "engrenar", mas quando consigo me dá uma satisfação muito grande! Sei que vão ter coisas a melhorar! Mas este movimento é muito bom!!!! Acredito que é a falta de hábito de escrever. Vou rebuscando e percebo os inúmeros assuntos que poderia escrever. Alguns artigos do tempo da graduação, outros da pós que eu poderia retomar escrevendo 
um pouco mais... Bom... Mas aí está o artigo para tua apreciação. (Professora T., 07/05/2011).

Conforme aumentava o grau de interação, a dificuldade própria do primeiro movimento de contato se rompia e o envio da primeira versão escrita acontecia. Consequentemente, os registros também passavam a revelar as razões dos "silenciamentos" e "ausências".

Tenho tantas inquietações... Não estou conseguindo focar... Já tentei... Escrevo frases soltas, desconexas... deleto tudo... e assim estou... Portanto, não tenho nenhuma linha... Mas vamos de novo... Até sexta vou tentar algo... Continuo em contato... Como os et's... Contatos imediatos... (Professora N., 28/03/2011).

Embora descrito como penoso, o processo de escrita sobre a atividade docente, considerando o conjunto de registros enviados aos professores pesquisadores via correspondência eletrônica, parece passar a ser entendido como estratégia eficaz para o processo de formação continuada e como potência para a aprendizagem da docência. É possível afirmar que a comunicação estabelecida via correspondência acabou se constituindo como campo de escuta, como lugar de apoio e ambiente de solidariedade. Um espaço-tempo em que aconteciam a interação e a conversação, ações próprias do movimento formativo e autoformativo, possibilidades que permitiram o exercício de fazer e refazer o pensamento e a escrita, de apostar em seu processo de autoria.

\section{A título de finalização: o destaque para os aprendizados}

A intenção da pesquisa-ação colaborativa, quando propõe o movimento da reflexão e da escrita, pretende desencadear um processo autoformativo. Ao ultrapassar as assessorias individualizadas e pontuais e propondo a escrita como estratégia formativa, assume-se um trabalho institucionalizado de acompanhamento comprometido com a efetiva qualificação dos profissionais da Educação Básica.

A pesquisa-ação fomenta um processo de formação continuada em colaboração, ou seja, professor-pesquisador da Universidade e professor-pesquisador 
na escola em permanente processo de discussão e reflexão sobre a ação docente que ambos realizam em seus contextos específicos.

Processos formativos que privilegiam a escrita também suscitam nos professores envolvidos sentimentos que, muitas vezes, são vividos pelas próprias crianças e adolescentes em sua condição de aprendizagem. Poder-se-ia dizer que, ao reviver tais sentimentos, cria-se, também, um espaço de interação em que o professor poderá colocar-se, novamente, na condição de aprendiz de sua própria ação de escrever, mesmo que em dimensões diferentes.

Ao experimentar e sentir-se parte de uma comunidade de aprendizagem da autoria escrita, enquanto aprendiz de autor, talvez o professor possa, a partir dessa experiência, ter mais recursos para entender e fomentar o processo de aprendizagem de autoria e reflexão que crianças e jovens de sua sala de aula vivem. Tal experiência poderá, especialmente, auxiliar a ampliar as formas de ação pedagógica a serem realizadas com as crianças que possuem algum tipo de necessidade educativa especial, principalmente quando na escola ainda há modelos pedagógicos que dificultam sua participação no processo de aprendizagem da leitura e da escrita. Por uma experiência similar cria-se, quiçá, condições que permitam ao profissional pensar sobre o que as crianças experimentam, mostrando, assim, que, talvez, não há processos estáticos ou fórmulas acabadas que levam à construção e ao aprendizado de um determinado conhecimento ou saber-fazer, como é o processo de pensar e escrever sobre o que se pensa e faz, vivido pelo professor em seu processo de autoria escrita.

Ao fazer uso da correspondência eletrônica talvez estejamos reatualizando a prática da correspondência pedagógica, algo muito utilizado por pedagogos em diferentes tempos, especialmente Freinet e, no Brasil, o educador Paulo Freire. Tal movimento provavelmente permitirá que as interlocuções entre professores da Educação Básica e da Universidade possam ser estreitadas. A facilidade e o acesso à internet, cada vez mais ampliados, talvez venham constituir, entre os professores de todos os níveis e modalidades de ensino, diferentes formas de intercâmbio e reflexões sobre a prática pedagógica.

A escrita como recurso formativo, especialmente quando faz do processo de formação continuada e de autoformação momento para valorizar o pensamento e a experiência docente do professor, estimula a autoria. Entretanto, sustentamos que o processo de escrita e autoria precisa estar situado em um contexto de ação e reflexão, voltado à socialização, para que possa desencadear novas reflexões e atividades coletivas no espaço em que a prática docente é produzida.

Embora tenha sido caracterizado como árduo, com marcas de uma solidão vivida durante seu processo, é possível considerar que, no contexto do campo empírico em análise, o exercício da escrita possibilitou reflexões que re-significaram conhecimentos práticos e teóricos. A escrita permite a construção 
de um tipo de abstração sobre o que se faz, induzindo a uma construção que também é simbólica, porque leva à sistematização de saberes docentes que, ao serem materializados através do código escrito, acabam ampliando atitudes investigativas e a própria ação pedagógica.

A atividade de escrita também se tornou um momento em que se deu visibilidade e se criou uma determinada organização para os saberes da prática que os profissionais desenvolvem. Ao mesmo tempo, o movimento de escrita produziu uma ruptura com a ideia de que o saber possa estar localizado na instituição de formação, especialmente na figura do professor-formador, de quem se espera receber prescrições pedagógicas para a atividade docente. Suspeitamos que o ato de escrever empoderou os professores e as professoras do centro para a sua tarefa enquanto formadores dos professores que atuam nas escolas da rede municipal. Por fim, conforme nosso entendimento, fazer uso da potência comunicativa que tal recurso possibilita é um desafio a ser perseguido como estratégia para ampliar e qualificar os processos de formação continuada. Todavia, também é um campo fértil para a construção de processos formativos com características mais democráticas, colaborativas e solidárias.

\section{REFERÊNCIAS}

ALARCÃO, Isabel. Professores reflexivos em uma escola reflexiva. 7. ed. São Paulo: Cortez, 2010. (Coleção: Questões de Nossa Época; v. 8).

BIANCHETTI, Lucídio. Estabelecendo interlocução no processo de autoria: o desafio de escrever dissertações e teses. In: SEMINÁRIO DA ANPEDSUL, 5., 2004, Paraná. Anais do V Seminário da AnpedSul. Curitiba: UFPR, 2008.

CARLOS, Lígia Cardoso; PEREIRA, Maria de Fátima Carneiro Ribeiro. A escrita como dispositivo de formação em educação. Cadernos de Educação, Pelotas, ano 20, n. 39, p. 175-192, maio/ago. 2011.

COMPIANI, Maurício. A pesquisa em formação contínua indicando passos na extensão e formação contínua. In: BARBOSA, Raquel Lazzari Leite (Org.). Formação de Educadores. Artes e técnicas - Ciências e Políticas. Campinas: Editora UNESP, 2006. p. 470-485.

CUNHA, Maria Isabel da. Conta-me agora!: As narrativas como alternativas pedagógicas na pesquisa e no ensino. Revista da Faculdade de Educação, São Paulo, v. 23, n. 1-2, jan./dez. 1997.

FRANCO, Maria Amélia Santoro. Pedagogia da pesquisa-ação. Educação e Pesquisa, São Paulo, v. 31, n. 3, p.483-502, set./dez. 2005. 
LEWIN, K. La investigación-acción y los problemas de las minorías. In: SALAZAR, María Cristina (Org.). La investigación: acción participativa. Inicios y desarrollos. Tradução: María Cristina Salazar. Madrid: Editorial Popular - Caracas: Editorial Laboratorio Educativo, 2006. p. 15-25.

LÜDKE, Menga. (Org.). O que conta como pesquisa? São Paulo: Cortez, 2009.

MALDANER, Otávio Aloísio. O professor-pesquisador: uma nova compreensão do trabalho docente. Espaços da Escola, Universidade de Ijuí, ano 4, n. 31, p. 5-14, jan./ mar. 1999.

MARCOLINO, Taís Quevedo; MIZUKAMI, Maria da Graça Nicolletti. Narrativas, processos reflexivos e prática profissional: apontamentos para pesquisa e formação. Interface (Botucatu), Botucatu, v. 12, n. 26, p. 541-547, jul./set. 2008.

NIETZSCHE, Friedrich. Assim falou Zaratustra. São Paulo: Martin Claret, 2006.

PINEAU, Gaston. O sentido do sentido. In: NICOLESCU, Basarab et al. Educação e transdisciplinaridade. Brasília: UNESCO, 2000.

PROFESSORA D.Artigo. Mensagem recebida por: <gilberto.ferreira65@gmail.com>, Canoas, em: 16/04/2011.

PROFESSORA G.Artigo. Mensagem recebida por: <gilberto.ferreira65@gmail.com>, Canoas, em: 02/05/2011.

PROFESSORA H. Artigo CEIA. Mensagem recebida por: <gilberto.ferreira65@gmail. com>, Canoas, em: 27/04/2011.

PROFESSORA L. Artigo CEIA. Mensagem recebida por: <gilberto.ferreira65@gmail. com>, Canoas, em: 01/04/2001.

PROFESSORA M. Artigo Pronto. Mensagem recebida por: < gilberto.ferreira65@gmail. com>, Canoas, em: 28/03/2011.

PROFESSORA M. Artigo. Mensagem recebida por: <gilberto.ferreira65@gmail.com>, Canoas, em: 13/04/2011.

PROFESSORA S. Artigo pronto. Mensagem recebida por: <gilberto.ferreira65@gmail. com>, Canoas, em: 11/04/2011.

PROFESSORA T. Artigo. Mensagem recebida por: <gilberto.ferreira65@gmail.com>, Canoas, em: 07/05/2011.

PROFESSORA T. Artigo. Mensagem recebida por: <gilberto.ferreira65@gmail.com>, Canoas, em: 07/04/2011.

REALI, Aline M. de M. R.; TANCREDI, Regina M. S. P.; MIZUKAMI, Maria da Graça Nicolletti. Programa de mentoria online para professores iniciantes: fases de um processo. Cadernos de Pesquisa, São Paulo, v. 40, n. 140, p. 479-506, maio/ago. 2010. 
WARSCHAUER, Cecília. Rodas em rede. Oportunidades formativas na escola e fora dela. São Paulo: Paz e Terra, 2001.

ZEICHNER, Kenneth M. Novos caminhos para o practicum: uma perspectiva para os anos 90. In: NÓVOA, Antonio. Os professores e sua formação. Lisboa: Dom Quixote, 1992, p. 115-138.

Texto recebido em 02 de abril de 2013. Texto aprovado em 18 de julho de 2014. 